\title{
Diabetes and depression cognitive therapy
}

\section{Introduction}

If you've ever sad or feelings of being depressed or saturated or exhausted his mind, as a person with diabetes, you're definitely not the only way. The American Diabetes Association describes depression as: ${ }^{1}$

Loss of pleasure has no interest in doing things you once enjoyed.

Change in sleep patterns: You have trouble falling asleep, waking up frequently during the night, or wanting to sleep more than usual, even during the day.

a. You wake up earlier than usual and cannot get back to sleep.

b. Changes in appetite: Eat more or less than usual, resulting in weight gain or rapid weight loss.

c. Concentration problems: You cannot watch a TV program or read an article because other thoughts or feelings get in the way. Remembering details or making decisions

d. Loss of energy: You feel tired all the time, not wanting to do things normally performed.

e. Nervousness: always feel so anxious you cannot sit still.

f. Feeling of Guilt: You feel you "never do anything right" and worry that you are a burden to others.

g. Feeling of sadness in the morning, feel worse in the morning than in the rest of the day.

h. In some cases self-destructive or suicidal thoughts feel that life is meaningless, you possibly believe it would be better to die than live a life with problems or are thinking of different ways of getting hurt, so sometimes unconscious.

i. Overeating or loss of appetite

If a person has three or more of these symptoms, or if you have only one or two, but felt bad for two weeks or more, it is time to ask for help.

A question that is often thought, but it does not say is:

Can people with diabetes have experience of past or be suffering a picture of Depression?

\section{Depression and diabetes}

A research study in the Archives of Internal Medicine, ${ }^{1}$ revealed that of the 23.5million Americans with diabetes, about 15 million of those people are also fighting bone Depression $63.8 \%$ over the bone half of the patients studied. If you have lived with diabetes for more than 5 seconds, then it is not difficult to understand why: the diabetes is non-stop bone a (WITHOUT STOPPING).

Besides being a situation we can say that is a box WITHOUT STOPPING, fluctuations in blood sugar levels in the blood, absolutely impact our energy, our brain function, in our behavior, motivations, dreams, hope, and is a factor increases the level of emotional stress in

\author{
Volume 3 Issue 8 - 2016
}

\author{
Lic Maria Belen Castiglione \\ Specialist in Clinical Psychology, National University of Ireland, \\ Europe
}

Correspondence: Lic Maria Belen Castiglione, Specialist in Clinical Psychology, Psychometrics Graduate, Postgraduate Diploma in Human Resources (RRHH) and Management Strategies, National University of Ireland, Galway (NUI Galway), Europe, Email belencastiglione@gmail.com

Received: August 10,2016 | Published: December 08, 2016

a person. Every time we see a number or parameter, which is related to values and quantitative get to have a good control of the disease (basal glycemia, controls Haemoglobin, control, Fundus, weight, goals etc.), if this is not a perfect result or not this close to the goal set by your therapist doctor, can experience a sense of emotional stress, whether we admit it or not, it is a situation that directly affects our self-esteem and expectations about the reality of the health of a person.

Every time we have to stop and take a pill or stop and provides an insulin injection every day, or just stop and look at the screen of the continuous glucose monitor or an insulin pump an exhibition, to be valued is experienced and expect this result, it can cause mild, moderate or severe feeling of emotional stress that making the treatment plan is obtained or not desired goals, for a better quality of life and longer life. And these circumstances described are only just a summary, a fraction of what it feels like to live with any type of diabetes: Stress, Frustration, Concern, Panic, Fear, Shame, Guiltily. In some cases feelings of resentment for thinking why is this happening to me? Hopelessness, Exhaustion, Confusion, Obsession.

Also, let's not forget the part sensation of pain in patients: for anyone being treated with insulin and control blood sugar levels in the blood every day, diabetes involves a daily dose of pain. Of course, little, small punctures and punctures, but added involve pain fractionally also controls overtime every day, are factors that add up to a concept of daily and frequent pain, which becomes part of the daily routine of these people.

In addition to possibly increase the risk of depression, diabetes can worsen symptoms of depression. The stress causes having to manage diabetes every day and the impact this disease has on the brain, they can contribute to the depression..$^{2,3}$ In the US, people with diabetes are twice as likely a average person to suffer depression. ${ }^{4}$

At the same time, some symptoms of depression can impair physical and mental health in general, not only increasing the risk of diabetes but worsen the symptoms of diabetes. For example, excessive intake of food can cause overweight, the main risk factor for diabetes. Fatigue or feeling of worthlessness can lead a person to ignore special diets or drug plans needed to control diabetes, worsening symptoms. Studies have shown that people with diabetes and depression have symptoms of severe diabetes than people who only suffer from diabetes. ${ }^{4}$ 
And before this described scenario, of a reality that diabetic patients they live day by day since they are diagnosed, what science offers us to address not only the Metabolic area or organic, but also the emotional?

A tool validates and impact on the patient's cognitive therapy.

\section{What is cognitive therapy?}

Further research at the Massachusetts General Hospital, ,,6 explains Psych Central, has focused on the effectiveness of treatment of depression in patients with type 2 diabetes through cognitive therapy. Cognitive therapy "is based on the concept that how we think about things that affect us and how we feel emotionally. Cognitive therapy focuses on today in thought, behavior and communication, rather than on past experiences and oriented towards solving practical problems of everyday life, "MedTerms explains.

Cognitive therapy has been applied to a wide range of issues, such as depression, anxiety, panic, fear, eating disorders, substance abuse and personality problems. Cognitive therapy is sometimes called cognitive behavioral therapy as it aims to help people in their thinking (cognitive) and ways in which they act (behavior). Cognitive therapy is used for example in the learning process in which an important role in the development and continuity of habits that help us control our emotions and seek positive solutions that help us overcome the feeling of emotional stress perform, the loss of hope and improve our habits in treatment, in this case a chronic disease.

In order to improve our quality of life and strengthen our selfesteem, to a sense of adversity, Diabetes, a chronic, non-communicable, and now despite the many scientific advances, is not a cure, but if multiple treatment options that can help us have a good quality of life, if we improve our habits, and discipline control, so the individual will have to learn to live with this condition or challenge, and manage to overcome the difficulties daily may occur. In other words, it comes to look at the way the way of thinking and feeling the effects of their emotions and behaviors, such as how to take care of your diabetes.

Improve and help control emotional state of patients with diabetes, it makes these have better adherence to specific therapeutic programs of their disease, so they will be more motivated, better willingness to integrate into their daily lives new habits to better control diabetes, such as activity physical, and make it more bearable and build selfesteem and have no feelings of guilt, or being unmotivated.

\section{Conclusion}

The association between depression and diabetes is well documented by clinical trials and show improvement in blood glucose control, when the patient is better addressed emotionally or has a frame of emotional support. Because diabetes is a disease that requires an immense amount of self-patient care, it makes sense to help a person with diabetes to strengthen thinking about his own illness and selfcare is a successful path to deal to the demands of the disease.

It is never easy for anyone, but if you are diabetic and have feelings or sensations that we describe in this article, I must say that it is normal for different times of life can pass through these stages, and the important message is do not be afraid the patient asking for help to treat your emotional state, because the more you let be, the harder it will be to resolve your situation and find coping mechanism to help us strengthen self-esteem.

\section{Acknowledgements}

None.

\section{Conflict of interest}

Author declares that there is no conflict of interest.

\section{References}

1. American Diabetes Association

2. Golden SH, Lazo M, Carnethon M, et al. Examining a bidirectional association between depressive symptoms and diabetes. JAMA. 2008;299(23):2751-2759.

3. Kumar A, Gupta R, Thomas A, et al. Focal subcortical biophysical abnormalities in patients diagnosed with type 2 diabetes and depression. Arch Gen Psychiatry. 2009;66(3):324-330.

4. Egede LE, Zheng D, Simpson K. Comorbid depression is associated with increased health care use and expenditures in individuals with diabetes. Diabetes Care. 2002;25(3):464-470.

5. Revista Archives of Internal Medicine.

6. Massachusetts General Hospital The MGH Depression Clinical \& Research Program (DCRP) is considered one of the leading centers for the study of Unipolar Depressive Disorders worldwide.

7. MedTerms. 